\title{
الكفاءة اللغوية ومستويات تحققها عند الطالب الجامعي
}

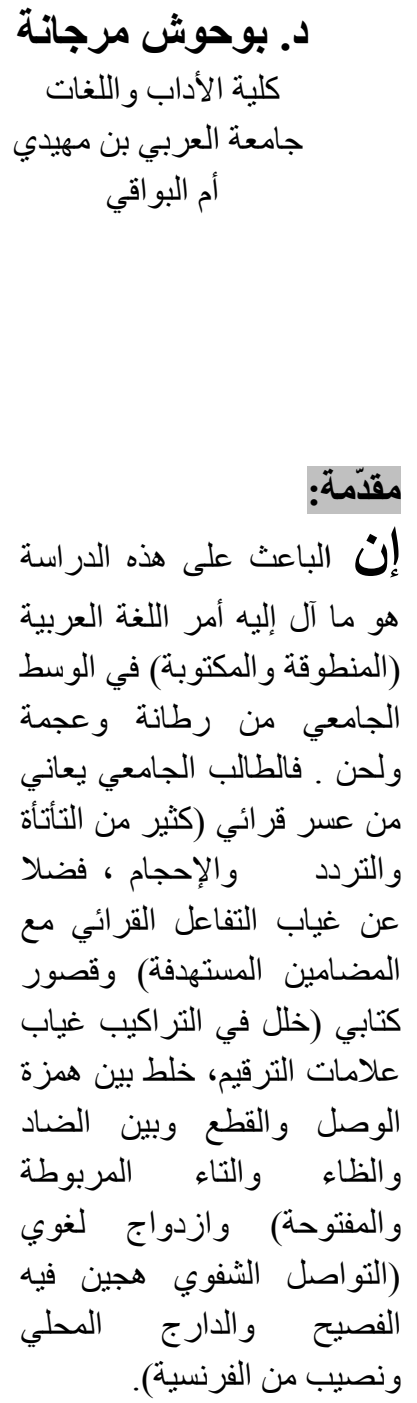

لا برقى التواصل اللغوي إلى مستوى الكفاءة اللغوية إلا إذا كان الأداء اللغوي كافيا

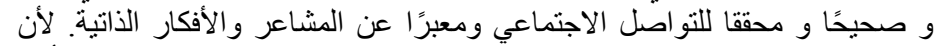

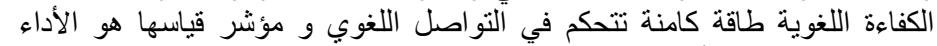

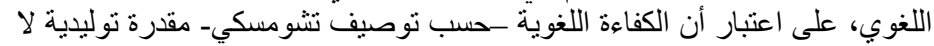
مقدرة تفسيرية ؛ مقدرة على الإنتاج و الفهم و التمييز.

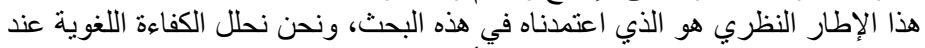

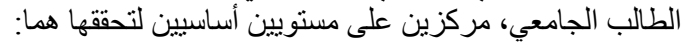

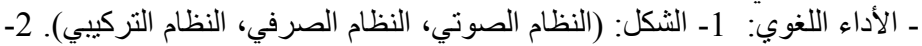

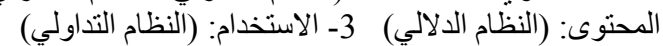
ــ الأداء المنهجي: 1- تحليل الخطاب اللغوي 2- استخدام الكصادر اللغوية 3- استعمال

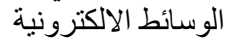
مفاتح الاراسة: الكفاءة اللغوية، الأداء اللغوي، مستويات التحقق، مؤشرات

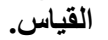

\section{Résumé:}

La communication linguistique ne peut être au même niveau que la compétence linguistique à moins que la performance linguistique soit suffisante, correcte, réalisant la communication sociale, et exprimant les sentiments et les pensées personnelles. La compétence linguistique est une énergie potentielle qui contrôle la communication linguistique, dont l'indice de sa mesure est la performance linguistique. Selon Chomski- la compétence linguistique est une capacité générative non interprétative (production de phrases non spécifiques par des méthodes spécifiques) c'est la capacité de production, de compréhension et de discrimination. Ce cadre théorique que nous avons adopté dans cette feuille de recherche, nous analysons la compétence linguistique chez l'étudiant universitaire, en se basant sur deux niveaux essentiels pour sa réalisation:

- La performance linguistique: 1.La forme: (système audio, système morphologique, système syntaxique). 2.Le contenu: (système sémantique)

3. Utilisation: (système pragmatique)

- La performance systématique: (1) analyse linguistique du discours 2. Utilisation des sources linguistiques 3. Utilisation des médias électroniques

Les clés de l'étude: la compétence linguistique, la performance linguistique, les niveaux de la réalisation, les indicateurs de mesure. 
يكاد يتفق معظم الدارسين على هذا التوصيف، لكن الاختلاف بينهم يكمن في أسباب هذا الضعف البيّن البيّن

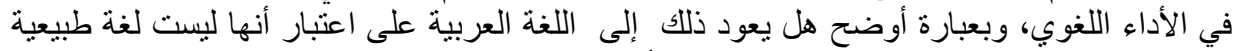

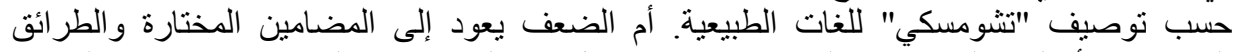

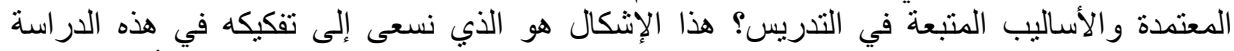

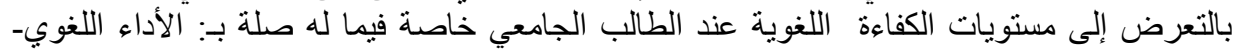
الثكل (النظام الصوتي و النظام الصرفي والنظام التركيبي) - و الدحتوى (النظام الدلالي) - و الاستخدام

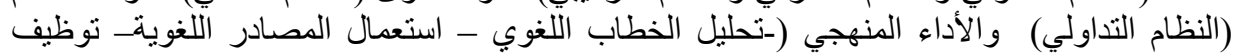

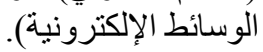
وما نتغياه ونستهدفه هو الخروج من دائرة التلقين والتكديس إلى دائرة التكوين والبناء، أي من حشو التهو

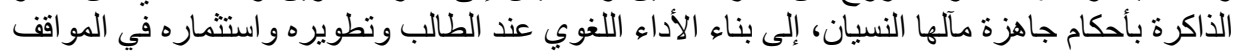
التواصلية المختلفة لتحقيق الكفاءة اللغوية.

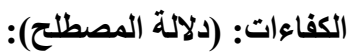

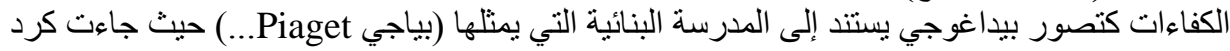

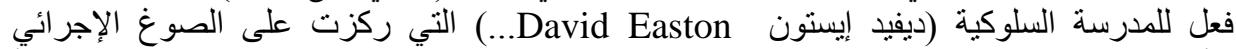

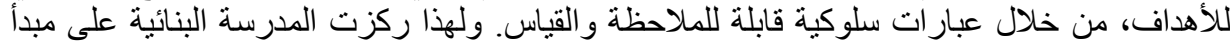

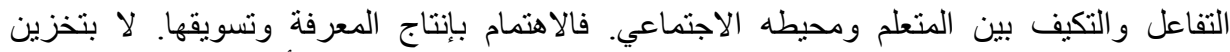

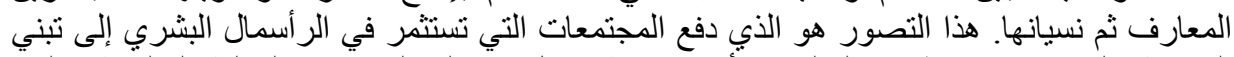

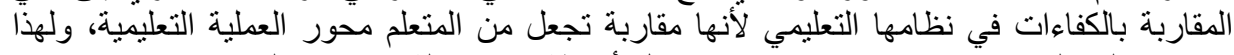

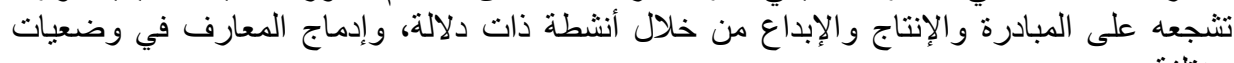

مختلفة.

وبغية الضبط و التمحيص لمصطلح (الكفاءات) حاولنا البحث في الدلالة اللغوية والدلالة الاصطلاحية

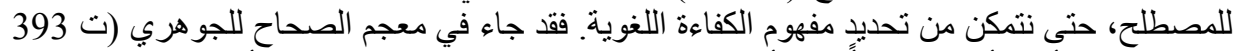

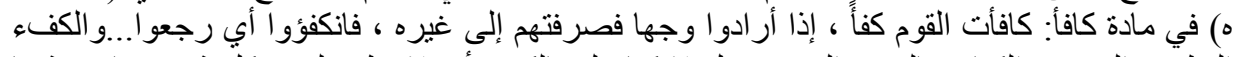

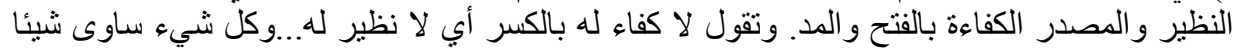

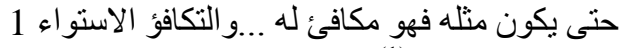

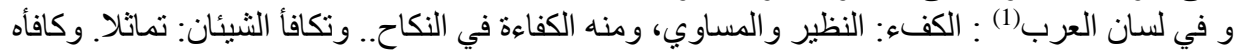

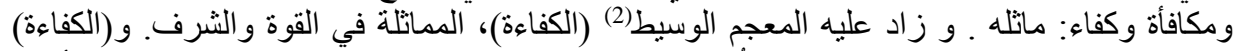

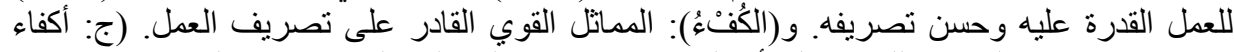

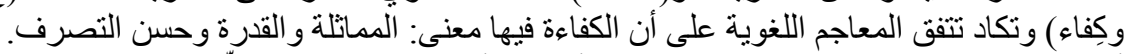

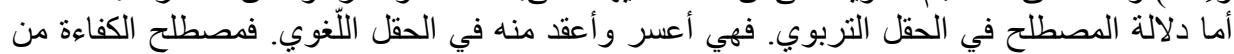

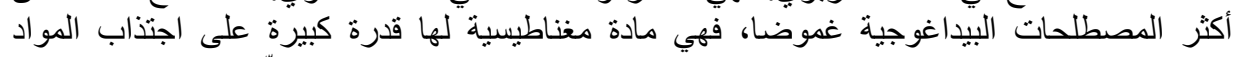

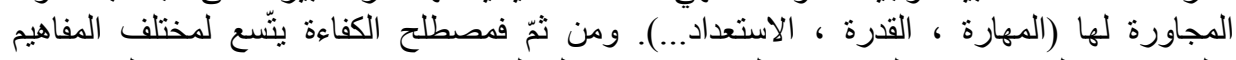

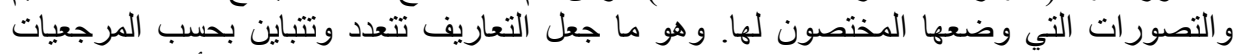

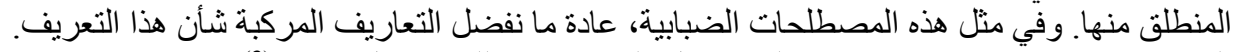

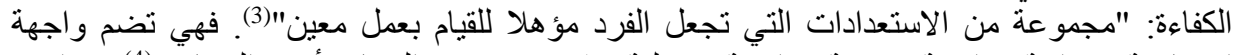

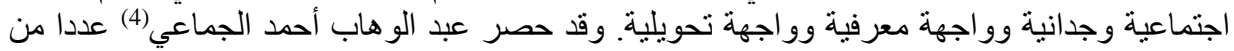
التعاريف للكفاءة نذكر منها:

تعريف رونالد Renauld هي: "قدرة مكتسبة بفضل ما تمثلك من معرفة وخبرة تستخدم للإحاطة وحل

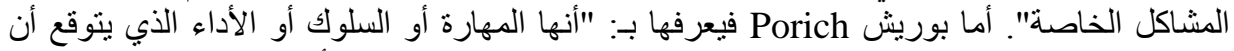

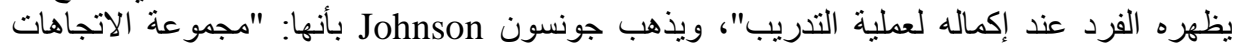
و المهار ات التي تظهر لدى المعلم في الموقف التعليمي". 
وتخلص الفتلاوي إلى أن المفهوم الإجرائي للكفاءة ينحصر في "قدرات نعبر عنها بعبار اتلات سلوكية

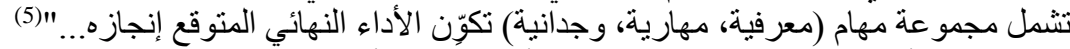

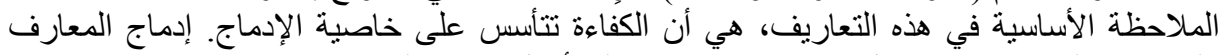

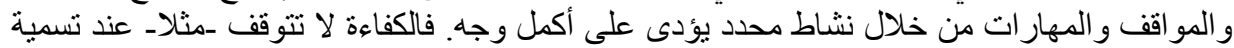

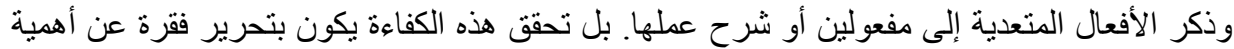

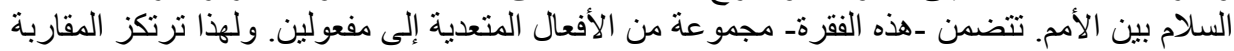

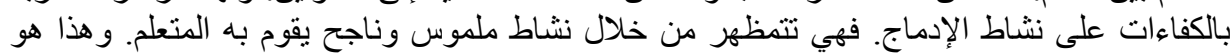

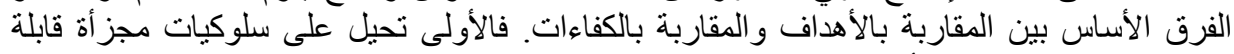

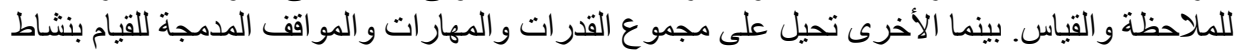

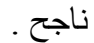

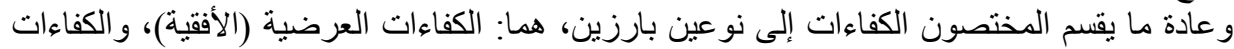

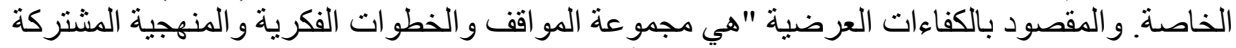

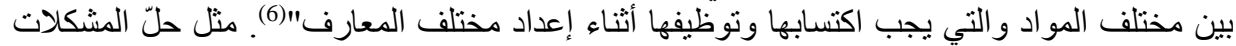

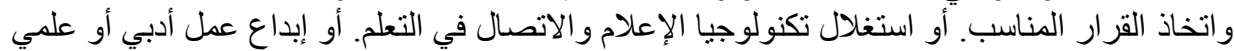

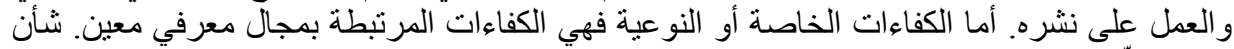

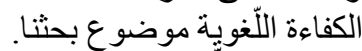

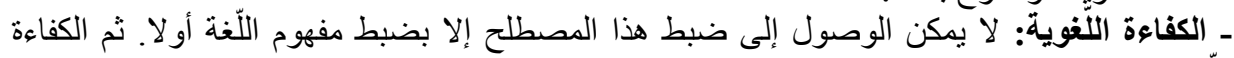
الألّغوية ثانيا. و انطلافا من نعريف "ابن جني" للّنة: "أصوات يعبر بها كل قوم عن أغر اضهم"(7) ومرور ا بالتعاريف

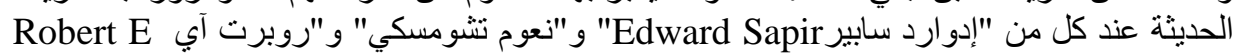
Owens

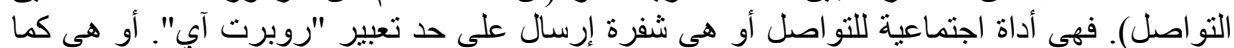

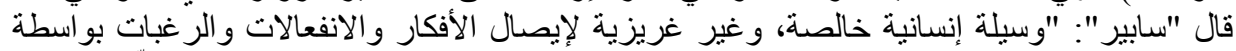

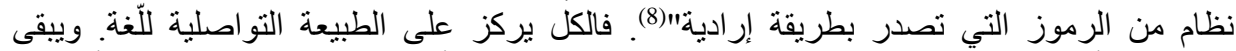

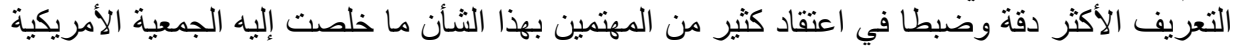

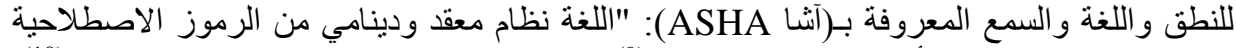

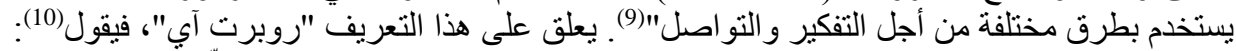

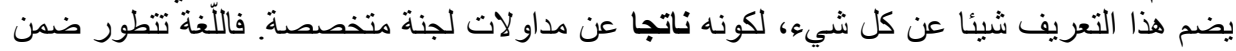

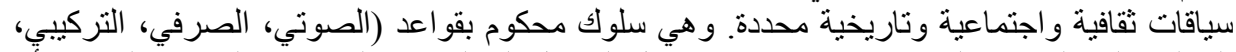

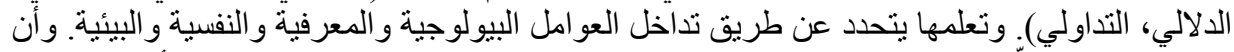
الاستخدام الفعال للّغة في التو اصل يتطلب فهما و واسعا للتفاعل الإنساني. وييقى الكلام هو الأداة المركزية

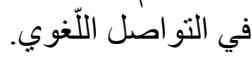
لكن السؤال الذي يطرح هو : متى ترقى الكفاعة اللغوية إلى مستوى التواصل اللغول اللغوي ؟ نقول: كلما كان

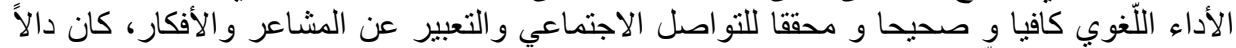

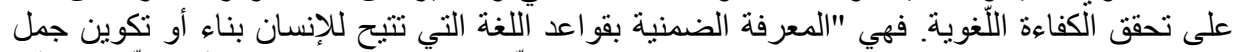

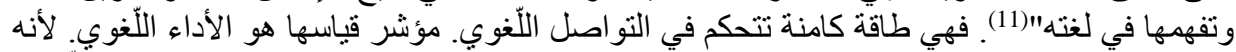

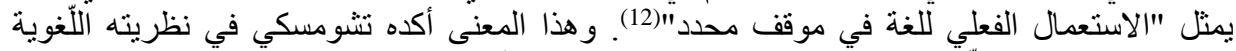
عندما اعتبر الكفاءة اللّغوية مقدرة توليدية لا مقدرة تفسيرية، أب هي قدرة على التى الإنتاج و الفهم و التمييز؛

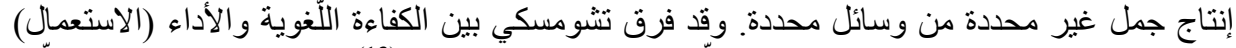

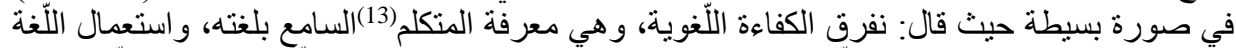

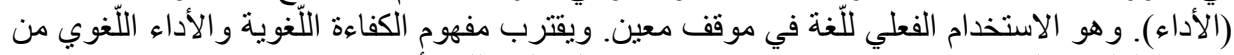

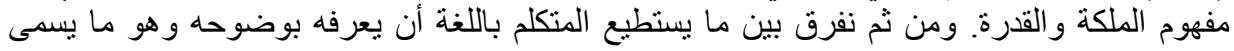


بالكفاءة وبين ما يسنطيع أن يفعله وهو ما بسمى بالأداء. والأداء هو ما يظهر على السطح. أما الكفاءة

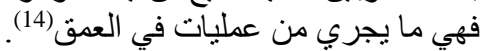

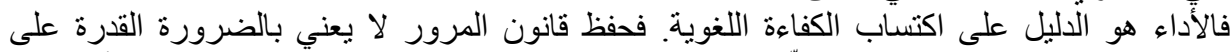

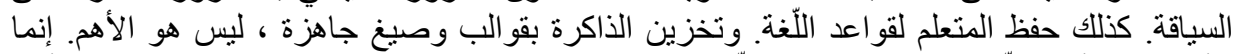
الأهم هو الأداء اللّغوي الفعلي للنظام اللّغوي. فالكفاءة طاقة كامنة يمكن ملامستها من خلال الألأداء

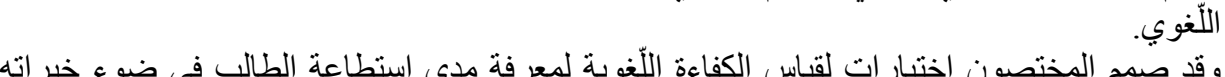

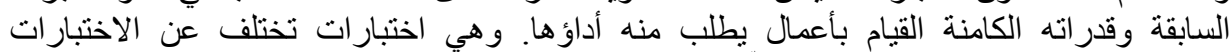

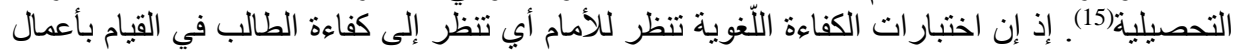

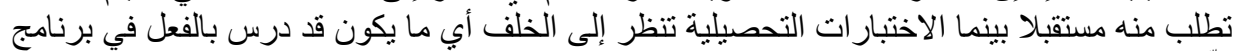

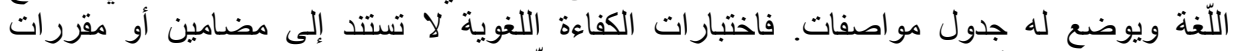

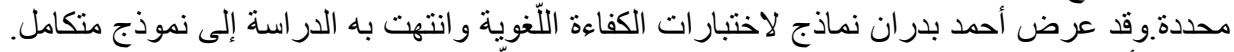

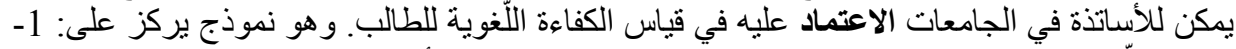

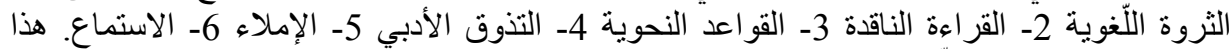

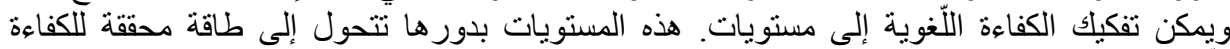
الألغوية.

مستويات تحقق الكفاءة اللّغوية:

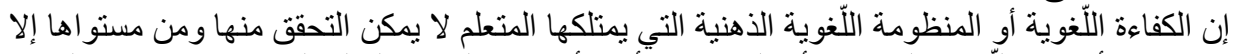

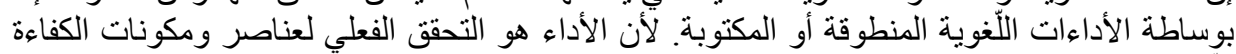

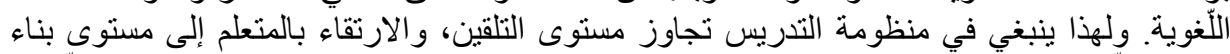

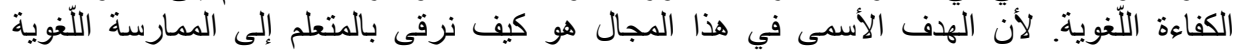

الصحيحة. هذه الممارسة يمكن ضبطها وحصر ها في مستويين أساسيين هما: الأداء اللّغوي و الأداء المنهجي.

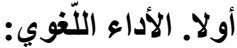

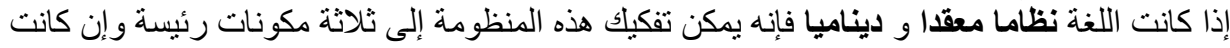

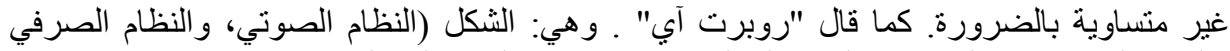
و النظام التركيبي)، و المحتوى (النظام الدلالي)، و الاستخدام (النظام التداولي) وهي:

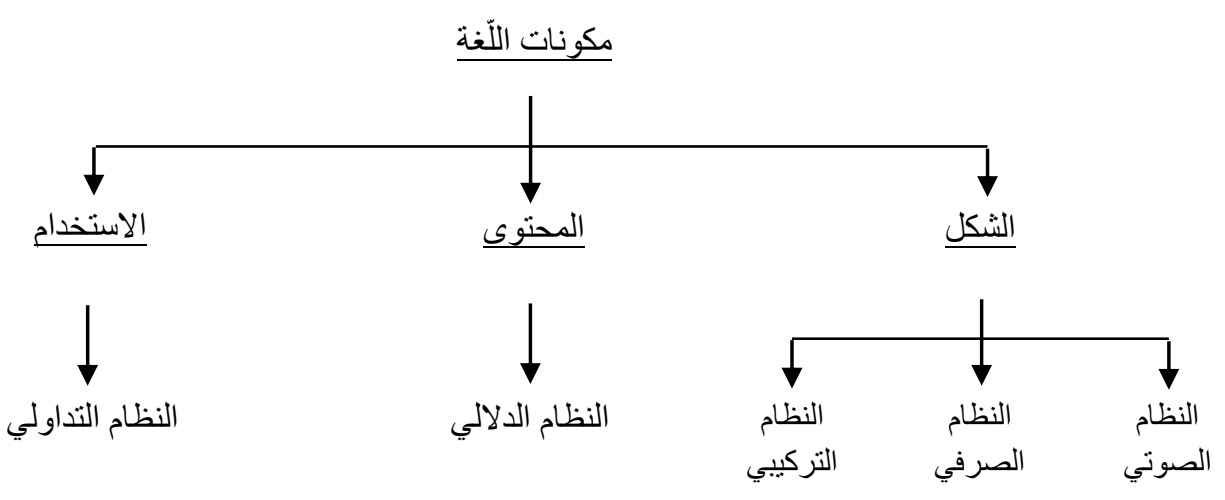


إن هذه المكونات هي أنظمة متداخلة، المتحكم فيها هو النظام التداولي فهو الدجال الحاكم أو المنظم(16).

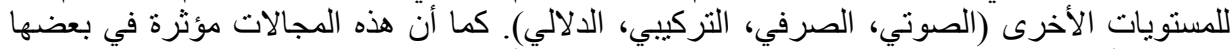

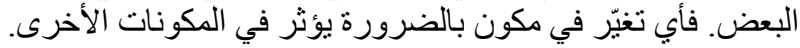

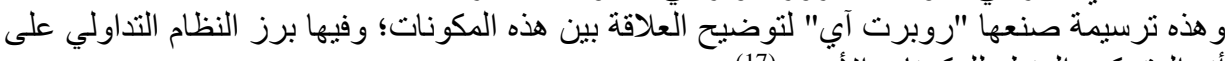
أنه المتحكم و الهنظم للمكونات الأخرى (17).

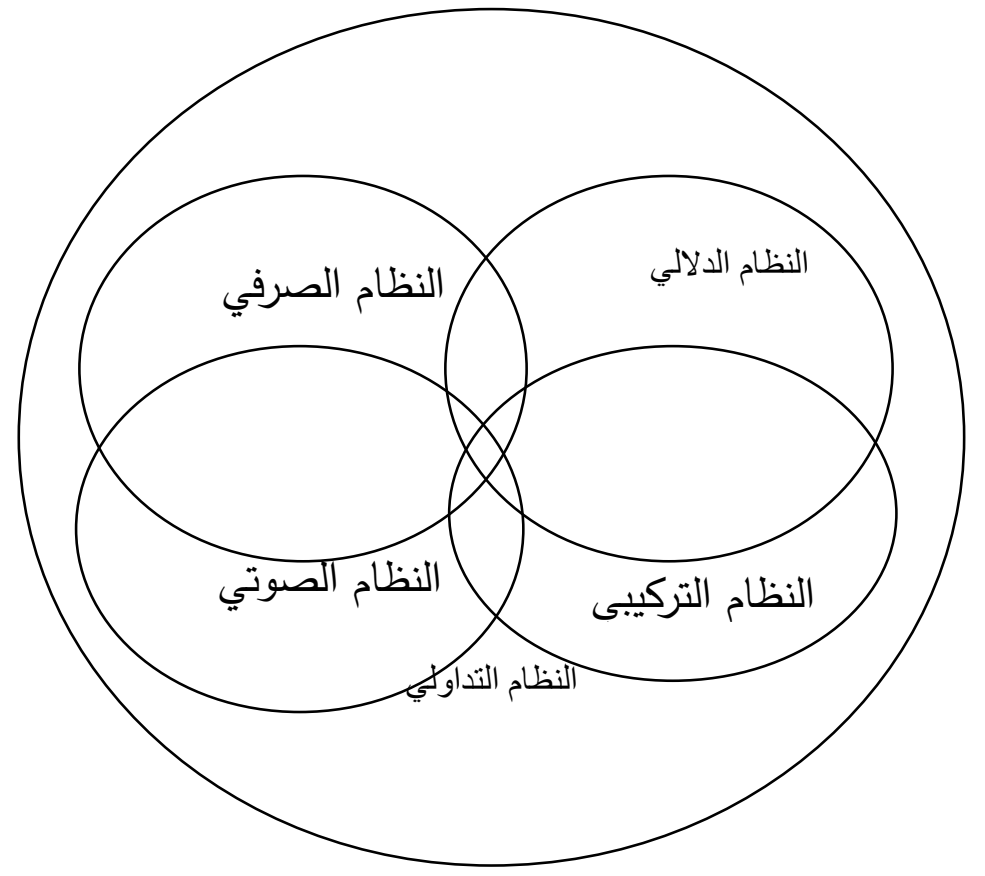

وحتى لا نبقى في مجال التنظير. نحاول تفصيل هذه المكونات، مع التمثيل لها بمفردات ومقرر ات لغوية يحتاجها الطالب الجامعي لاكتساب الكفاءة اللّغوية:

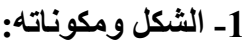

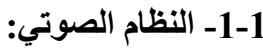

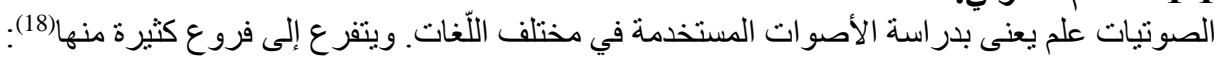

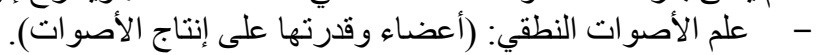

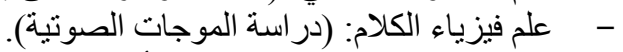

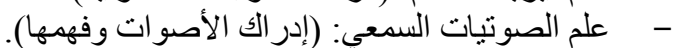

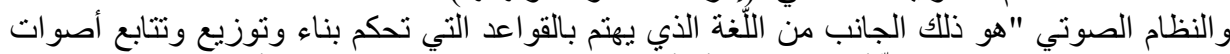

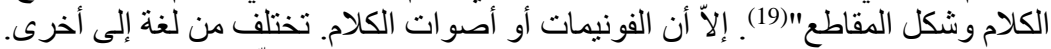

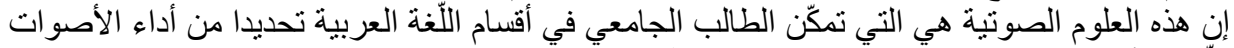

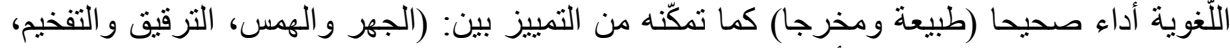

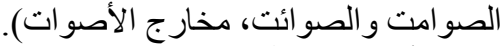

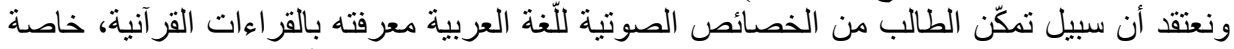

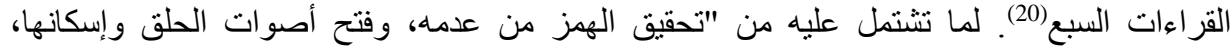




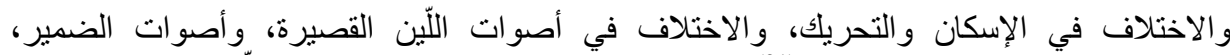

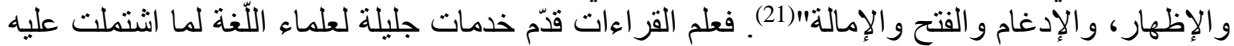

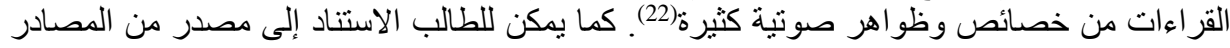

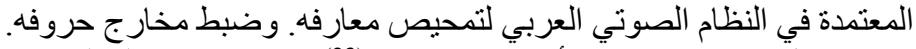
و هذا جدول خاص في بمخارج الأصؤات وصفاتها(23)، يدقق معارف الطالب ويمحصها في هذا المجال(24).

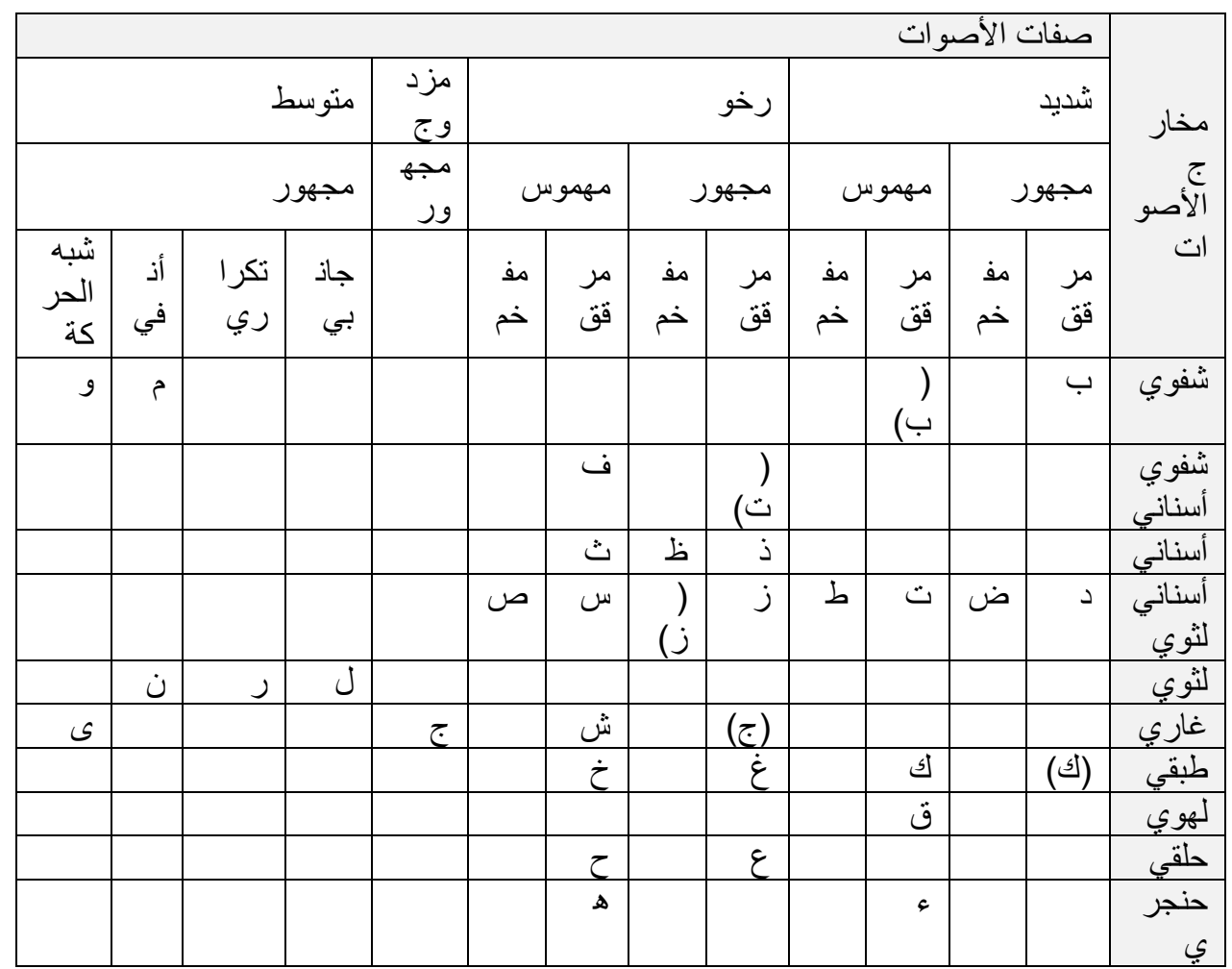




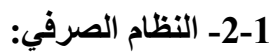

يجتم النظام الصرفي بأحوال أبنية الكلمة. ويتحقق الأداء اللّغوي في هذا المستوى إذا تمكّن الطالب

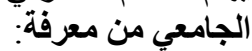

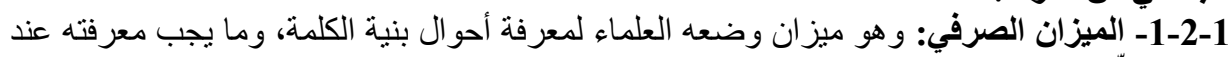

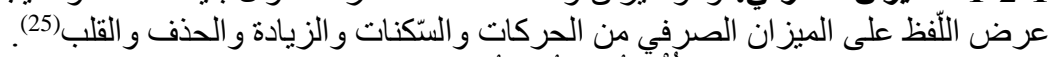

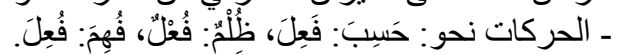

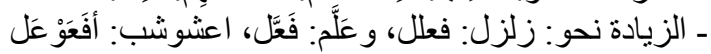

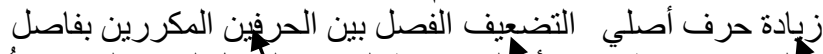

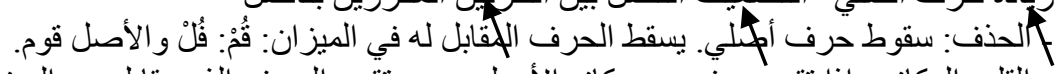

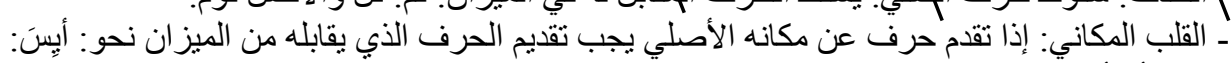

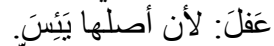

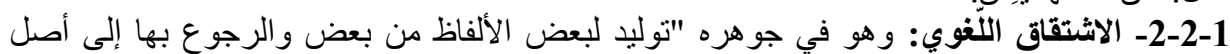

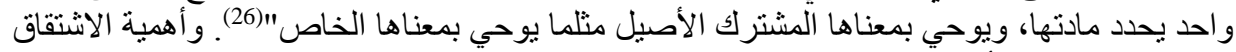

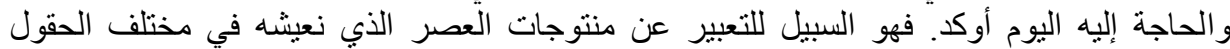

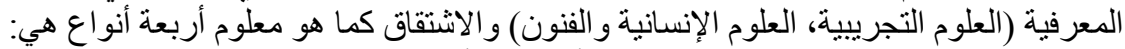

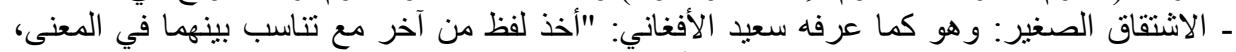

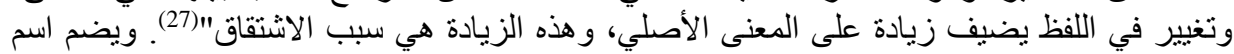

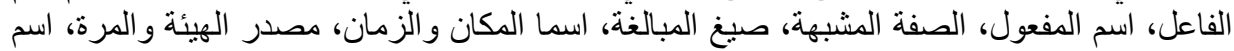

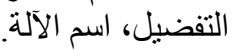

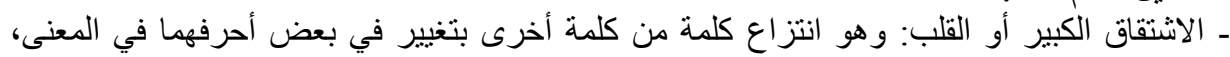

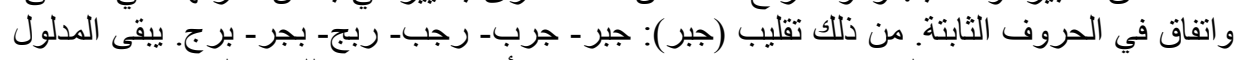

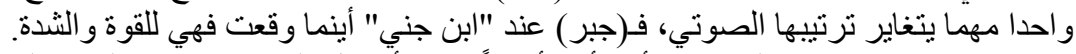

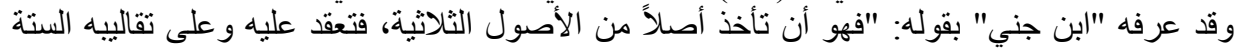

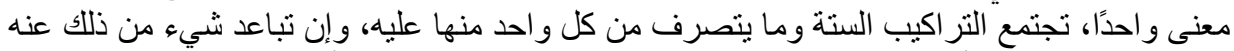

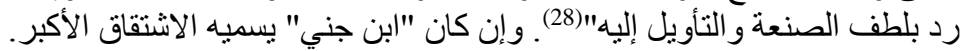

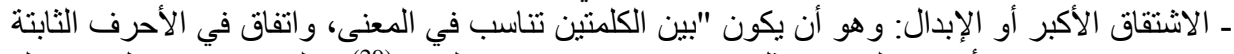

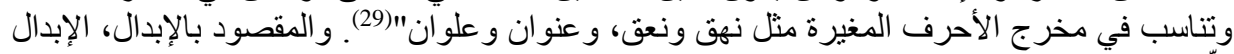

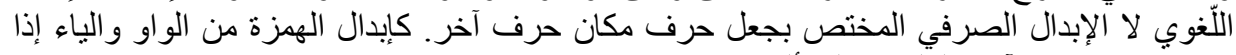

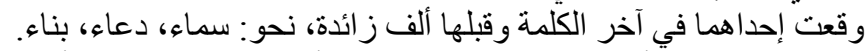

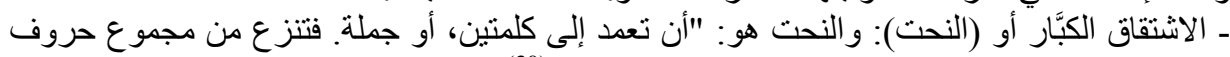

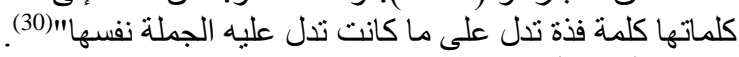

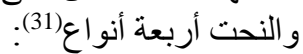

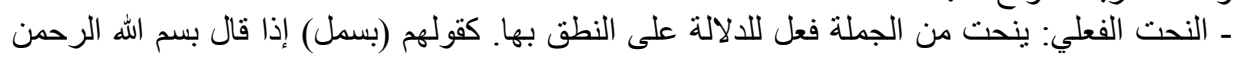

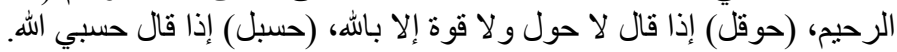

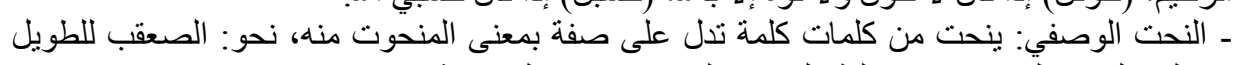

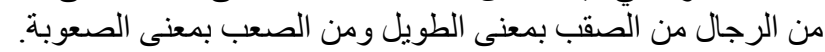

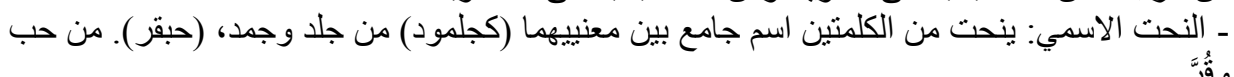
ــ النحت النسبي: يكون بأن ينحت اسم منسوب إلى علمين، كقولهم شفعنتي: نسبة إلى الثافعي وأبي

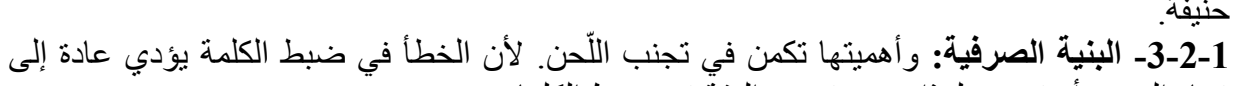

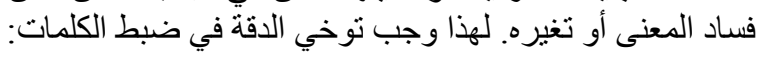


ـ ـنقول: الثاعر المتوفي و الصواب المتوفى لأن المتوفي هو الله.

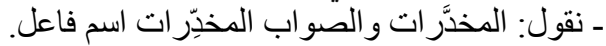

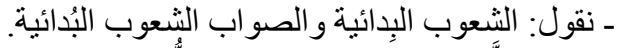
ـ ـ نقول: الثَّكنة العسكرية و الصوبة الصواب الثُّنة العسكرية.

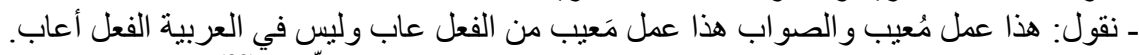

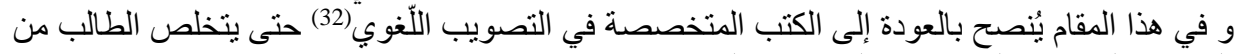

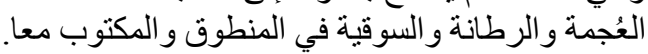

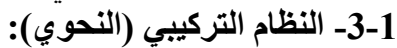

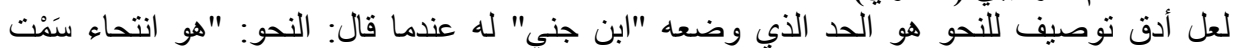

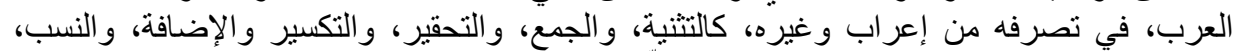

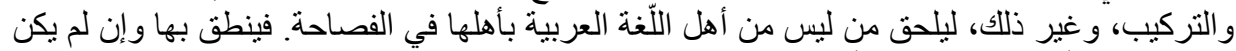

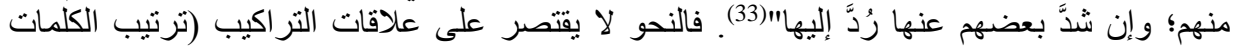

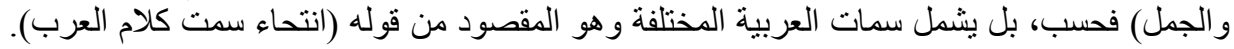
ولهذا فالمستوى التركيبي (النحوي) يشمل: الإعراب و العو امل النحوية وقو اعد تركيب الجملة، وعلافاتهات النها

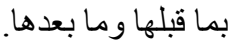
ويؤكد أحمد المتوكل "على أن الإعراب في اللغة العربية إعرابان: إعراب بنيوي وإعراب وظيفي"(34).

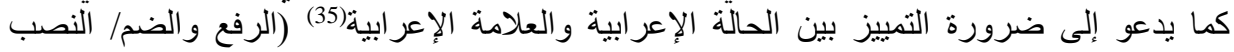

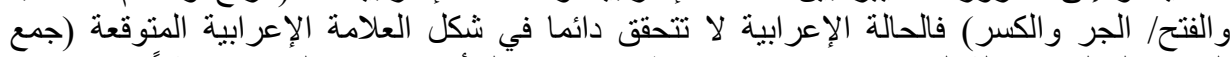

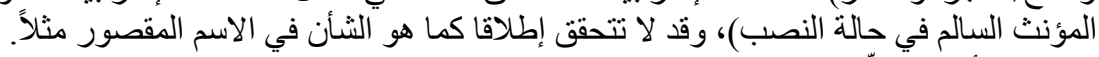

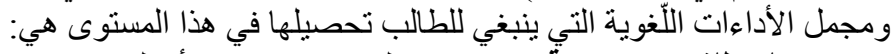

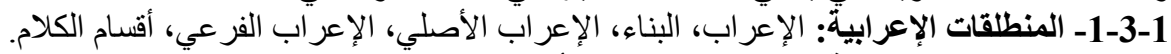

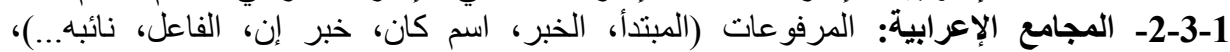

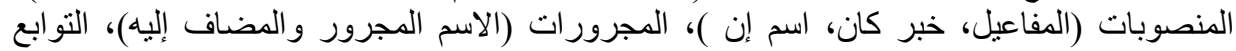
(النعت، البدل، التوكيد، العطف خلفئ...). -3-3-1 الأساليب النحوية ووظائفها: أسلوب التعجب، أسلوب المدح، أسلوب الذم، أسلوب الاستفهام،

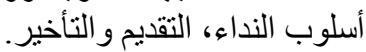

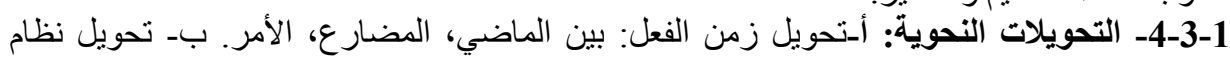
الجملة: الاسمية، الفعلية، المثبتة، المنفية، الخبرية، الفية، الإنثائية.

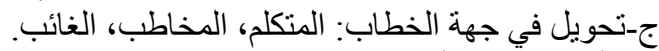

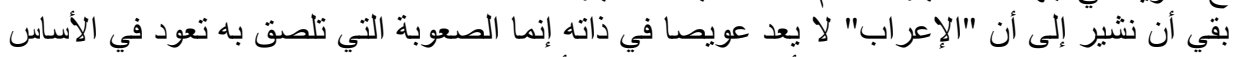

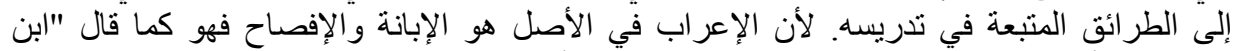

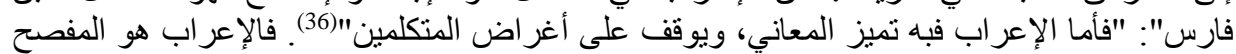

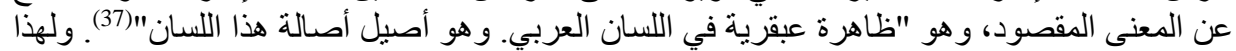

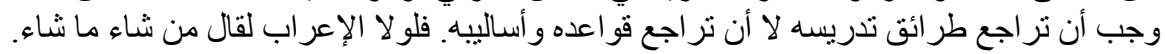

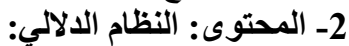

أهمية هذا المستوى تكمن في أن المستويات السابقة (الصوتي، الصرفي، الصني، النحوي) تعد تابعة له، فهي

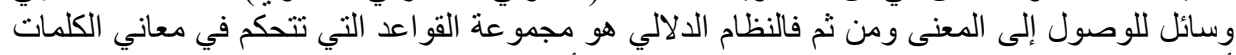

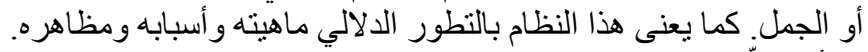

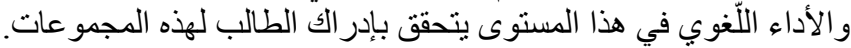

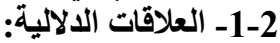

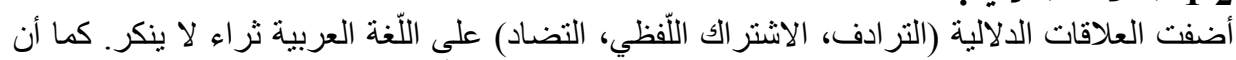

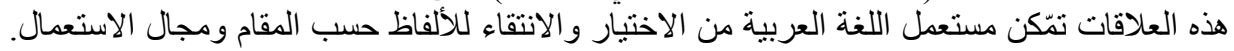




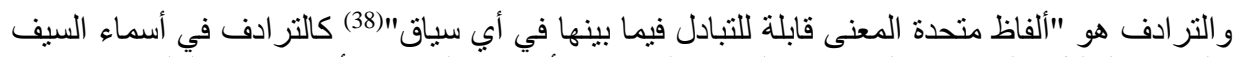

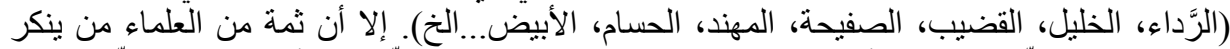

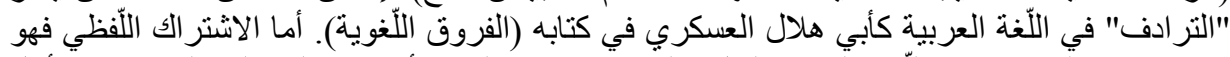

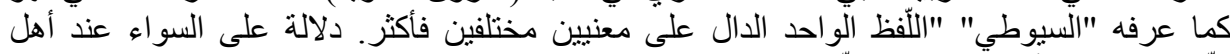

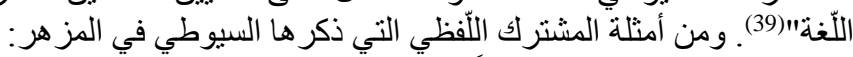

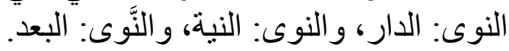

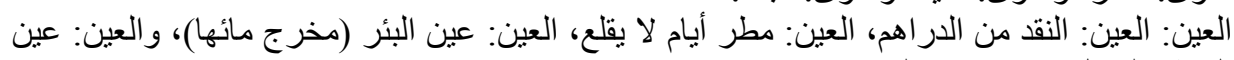

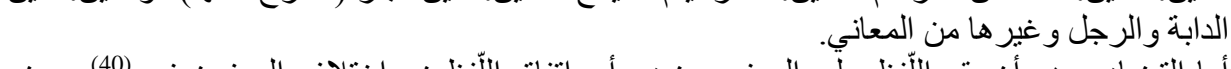

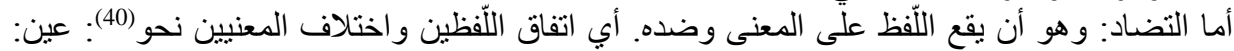

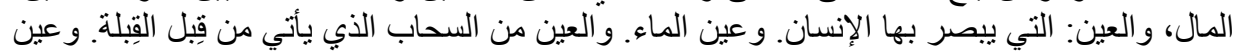

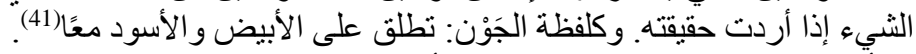

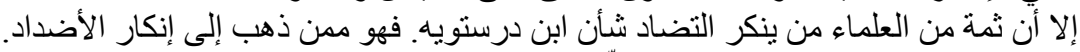

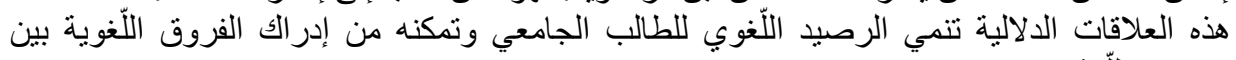
مفردات اللَّة.

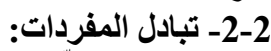

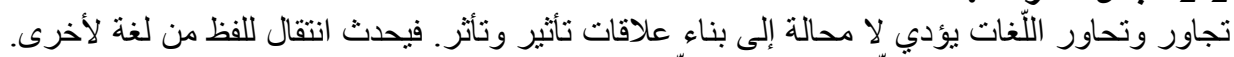

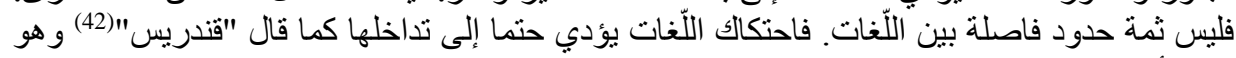

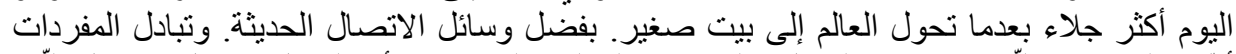

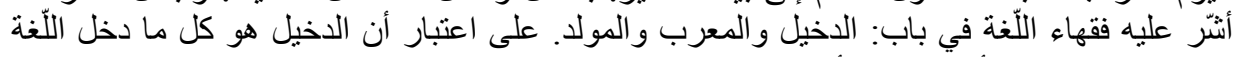

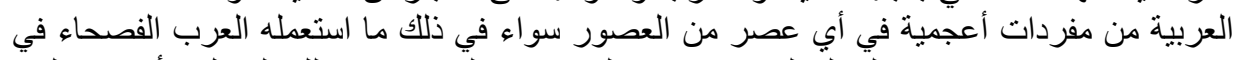

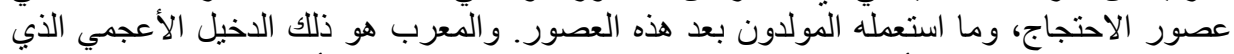

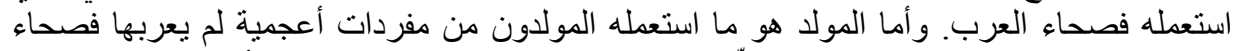

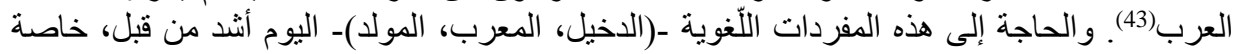

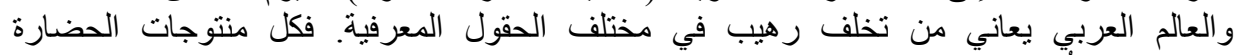

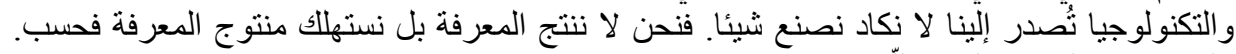

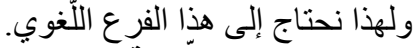

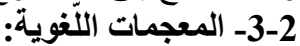

المعجم كثثَّف لغوي يشمل كلمات لغة لغة ما مرتبة ترنيبا معينا قصد شرحها وبيان معانيها المختلفة.

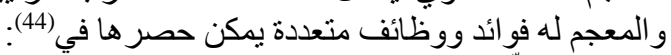

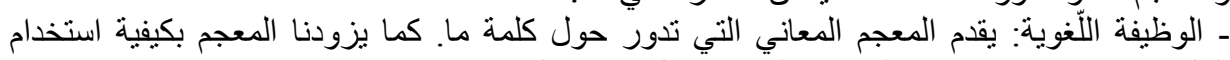

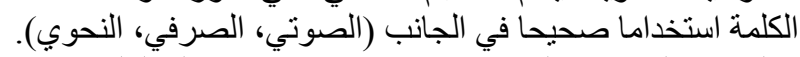

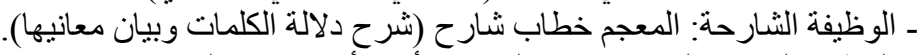

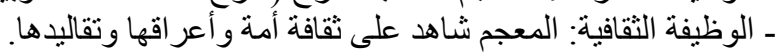

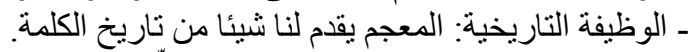

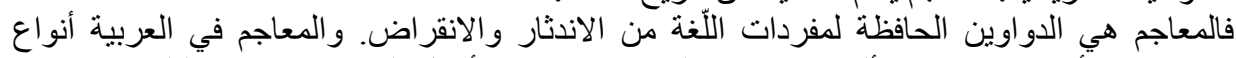

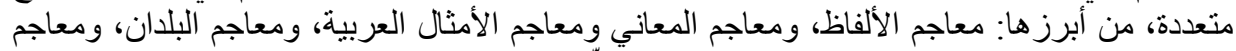

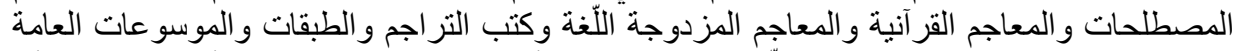

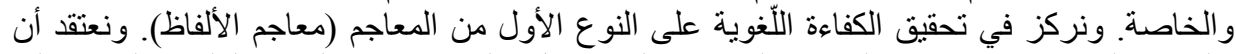

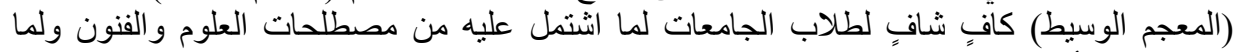

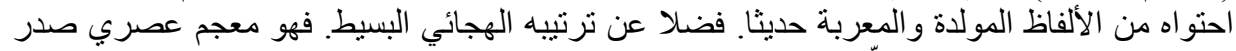

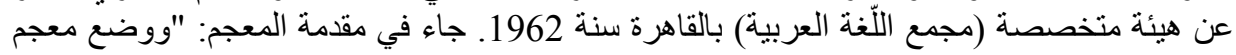


يقدم إلى القارئ المثقف ما يحتاج إليه من مواد لغوية، في أسلوب واضح قريب المأخذ. سهل التناول"(45). مع الابتعاد عن اللَّظ الغريب الحوشي و التزرفع عن التلّفظ الهجين السوفي.

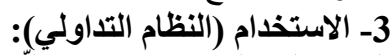

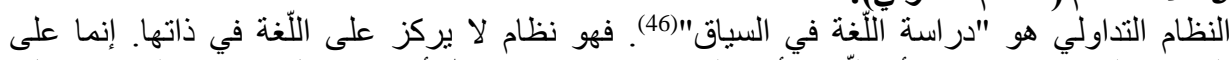

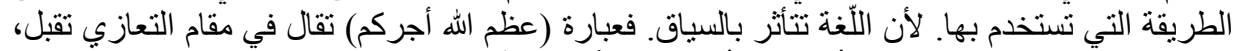

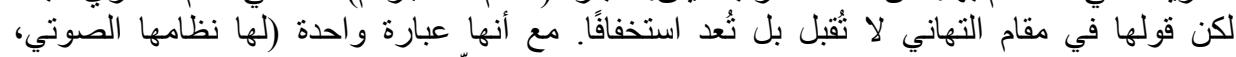

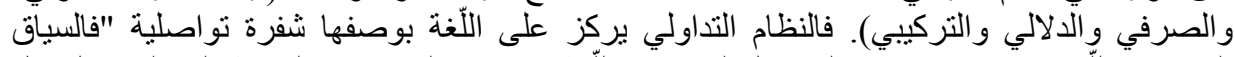

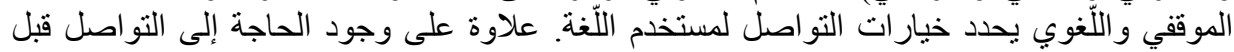

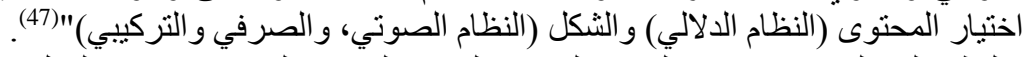

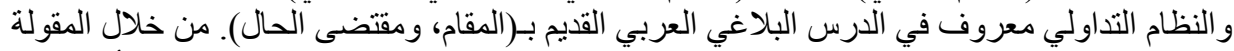

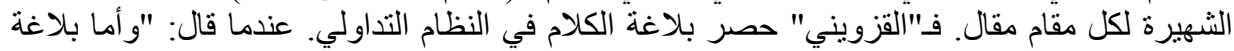

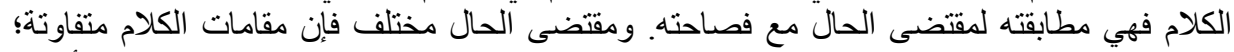
فمقام التتكير يباين مقام التعريف، ومقام الإطلاق يباين مقام التقييد، ومقام التقديم يباين مقام التأخير، ومقام الفصل يباين مقام الوصل...."(48).

فكل موقف تخاطبي تحكمه مجموعة من العناصر هي: "زمان التمان التخاطب ومكانه وعلاقة المتكلم

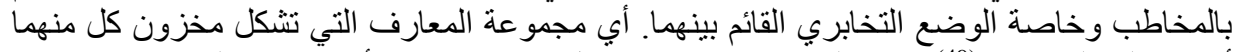

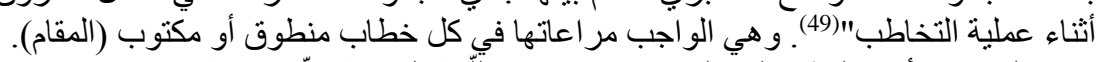

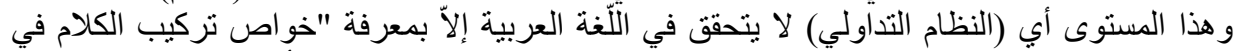

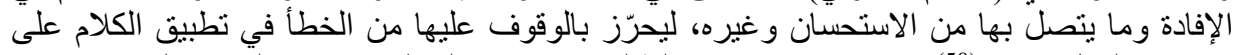

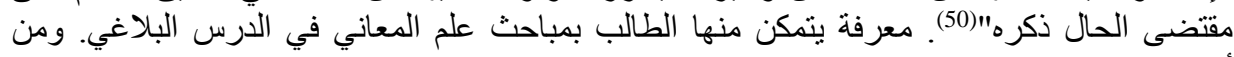

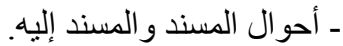
ـ - تقسيم الكلام إلى خبر و إنشاء.

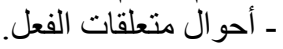
ـ ـ مباحث: القصر ، الفصل، الوصل، الإيجاز، الإطناب، المساو اة، التقديم، التأخير...

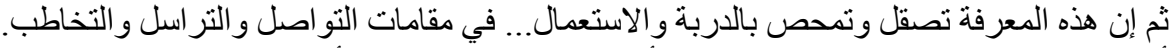

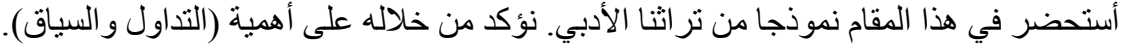

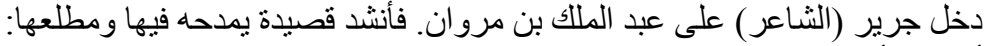
عشية همّ صحبك بالرواح بهاح

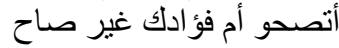

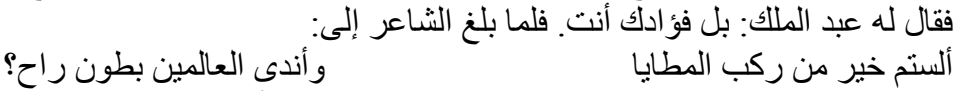

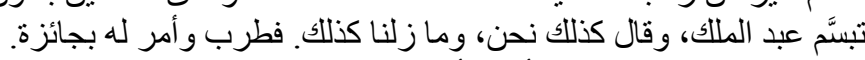

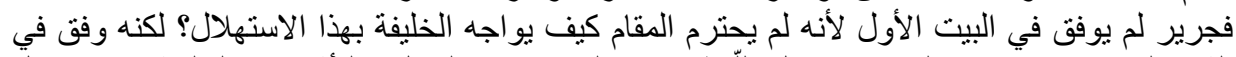

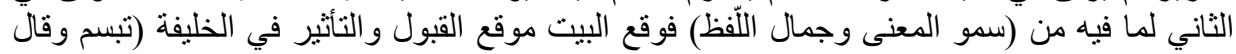

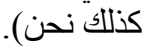
فيجب مر اعاة أحوال المخاطب. و "اعتبار طبقاتهم في البلاغة وقوتهم في البيان و المنطق، فللسوقة كلان كلام لا يصلح غيره في موضعه و الغرض الذي يبنى عليه، ولسراة القوم والأمراء فن فئن آخر لا يسد مسده

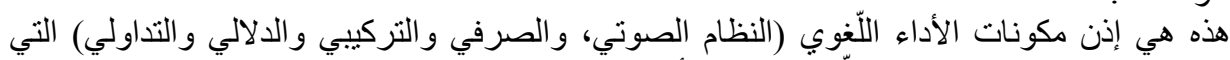
بحتاجها الطالب لتحقيق كفاءته اللّغوية. ييقى الأداء الآخر و هو: 
و المقصود به قدرة المتعلم -في أقسام اللغة العربيةـ على التواصل الإيجابي مع مصادر اللّغة، وعلى

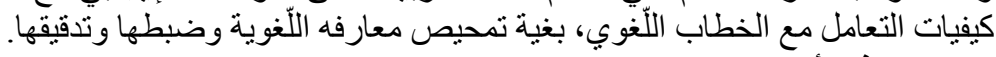
ويتحقق هذا الأداء المنهجي بـ المباب :

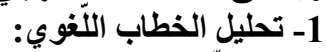

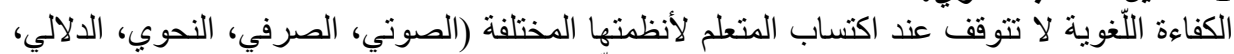

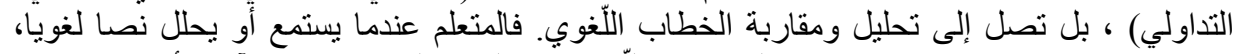

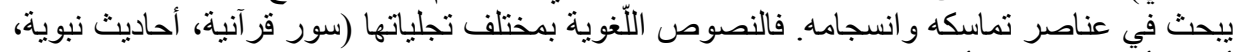

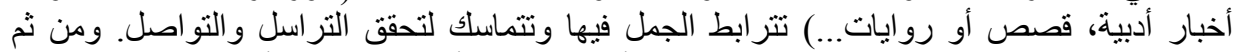

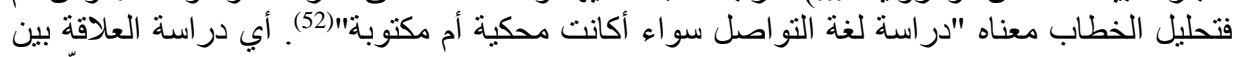

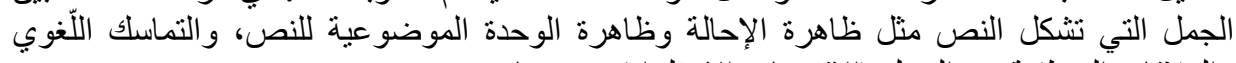

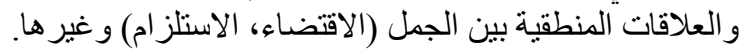

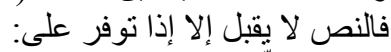

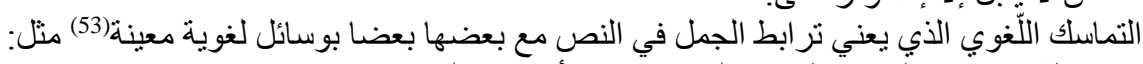

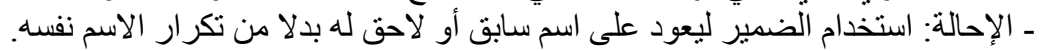
ـ الربط: بوساطة الحروف (حروف العطف مثلا)، وثمة ألفاظ أو كلمات للتر ابط مثل (على سبيل المثنال،

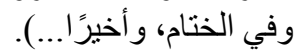

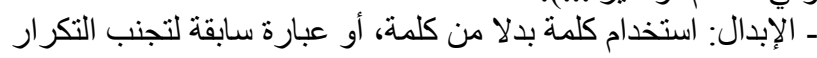

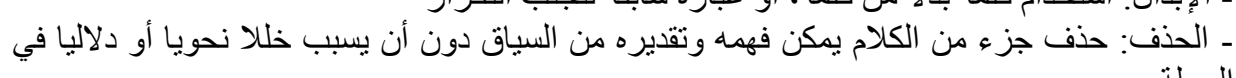

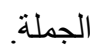
هذه الوسائل و غير ها تؤكد على التماسك اللغوي في النص.

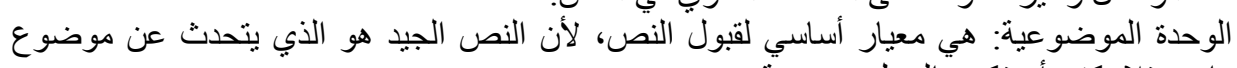
واحدة. فلا يكفي أن تكون الجمل صحيحة.

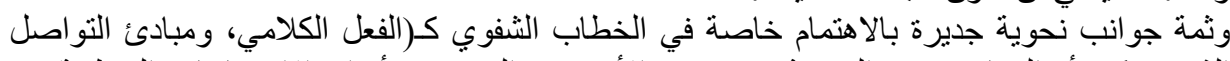

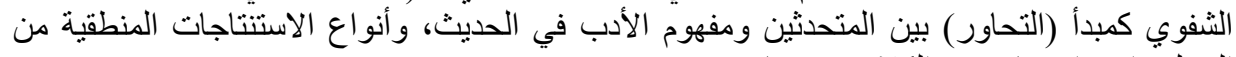

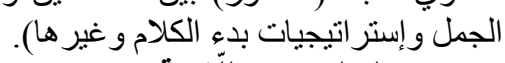

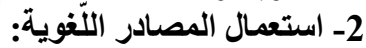

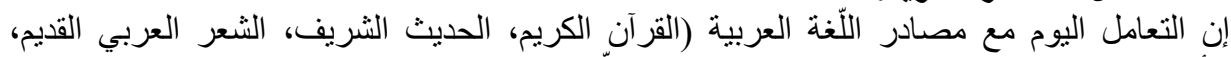

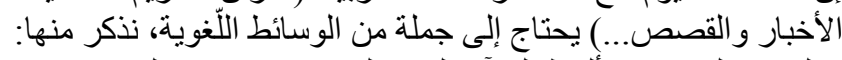

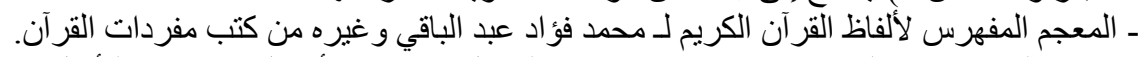

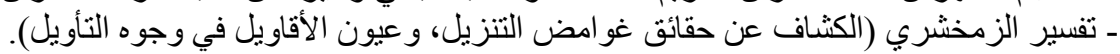

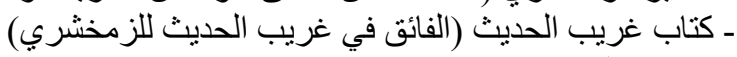

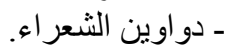
ـ ـ كتاب في تر اجم الأعلام (إرشاد الأريب إلى معرفة الأديب، معجم الأدباء لياقوت الحموي).

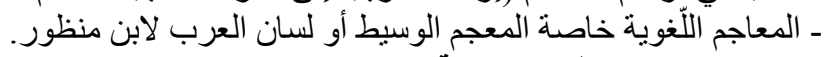
3- 3- استعمال الوسائط الإكترونية:

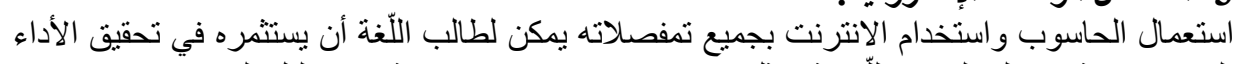

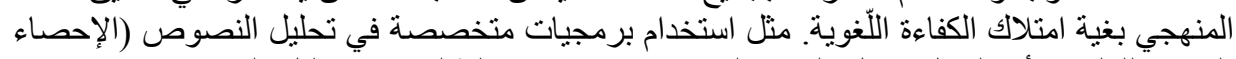

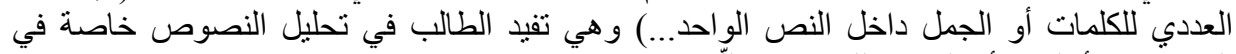

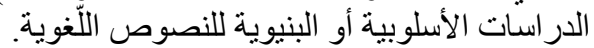

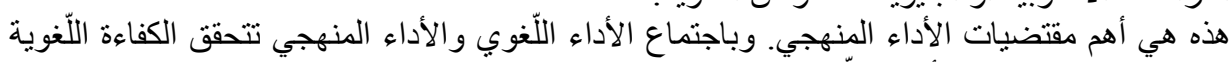
عند الطُالب الجامعي في أقسام اللّغة العربية. 


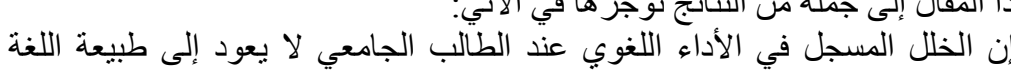

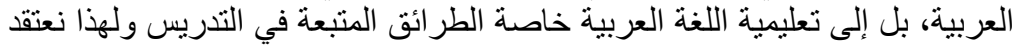

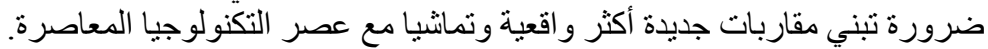

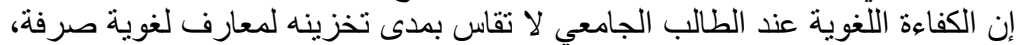

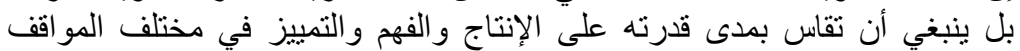

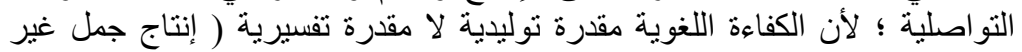
محددة من وسائل محددة).

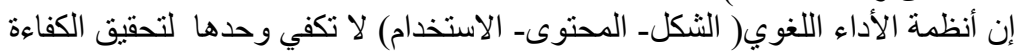
اللغوية، لهذا وجب الأهتمام بتحقق الأداء المنهجي ( تحليل الخطاب اللغوي الأبكاب ، استخدام

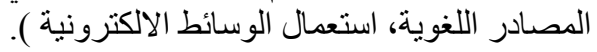


1. ابن جني: الخصائص، تحقيق محمد علي النجار، المكتبة العلمية، (د.ت). 2. ابن فارس (ابو الحسن): الصاحبي في فقله اللّغة العربية ومسائلها وسنن العربة العرب في كلامها،

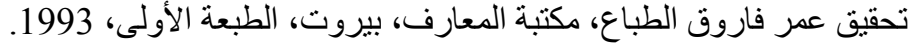

3. ابن منظور: لسان العرب، دار المعارف، مصرة، طبعة جديدة محققة ومثكولة، المجلد

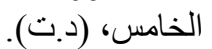
4. بدران (عبد المنعم): مهار ات ما ور راء المعرفة و علاقتها بالكفاءة اللّغوية، العلم و الإيمان للنشر

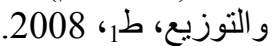

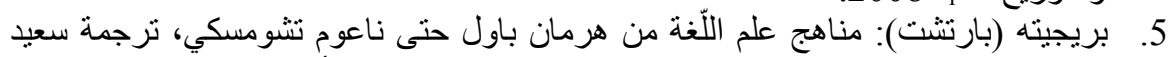

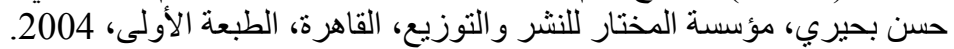

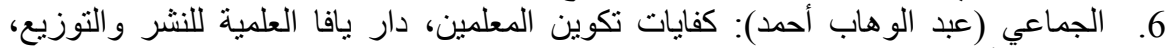

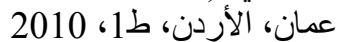

7. حاجي (فريد) وأويدر (عبد الرزاق): الكفاءات العرضية، المركز الوطني للوثائق التربوية،

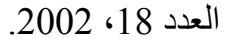

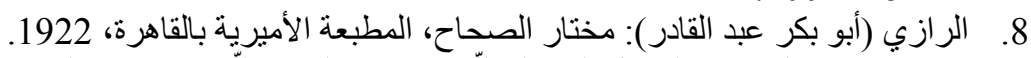

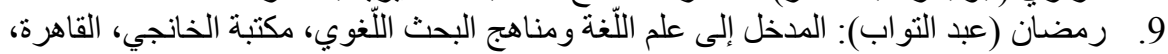
الطبعة الثانبة، (اعبد) 1980.

10. روبرت (آي): مقدمة في التطور اللّغوي، ترجمة مصطفى محمد قاسم، دار الفكر، عمان،

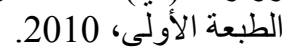

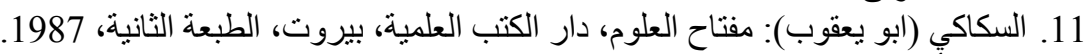

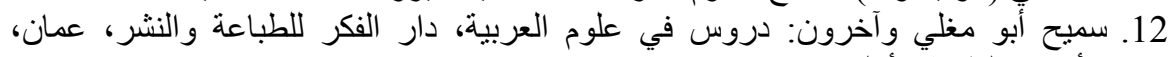

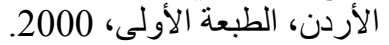

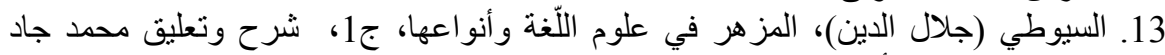

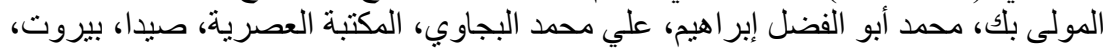
1987

14. شحده (فارغ)، محمد (العناني) وآخرون: مقدمة في اللّغويات المعاصرة، دار وائل للنشر ، الطبعة الأولىى، 2000. 15. صبحي (الصالح): دراسات في فقه اللّنة، نقلاً عن محمد أسعد النادري، فقه اللّغة مناهله ومسائلَ، (د.ت). (15). 16. الفتلاوي (سهيلة محسن كاظم): الكفايات التدريسية، الدفهوم ـالتدريبـالأداء، دار الثروق

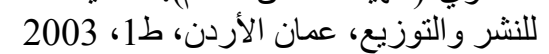
17. القزويني الخطيب: الإيضاح في علومن الإدي، البلاغة، دار إحياء العلوم، بيروت، الطبعة الأولى، .1988 18. المتوكل (أحمد): الدنحى الوظيفي في الفكر اللّغوي العربي (الأصول والامتداد)، دار الأمان،

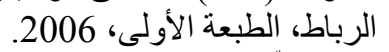
19. مجمع اللّغة العربية (مجموعة من المؤلفين): المعجم الوسيط، ج2، دار المعارف، مصر، الطبعة الثانية، 1973. 1973.

20. مجمو عة من المؤلفين: المعجم الوسيط، الطبعة الثانية، 1973.

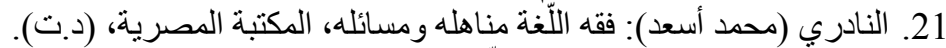
22. نمر (هادي): الأساس في فقه اللّغة العربية وأرومتها، دار الفكر، عمان، الأردن، الطبعة

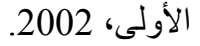


23. الهاثمي (السيد أحمد): جواهر البلاغة في المعاني والبيان والبديع، دار الكتب العلمية،

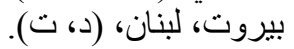

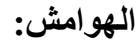

1- ابن منظور: لسان العرب، دار المعارف، مصر، طبعة جديدة محققة ومشكولة، المجلد الخامس،

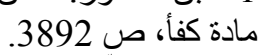
2- مجع اللَّة العربية (مجموعة من المؤلفين): المجم الوسيط، دار المعارف، مصر، الطبعة الثانية،

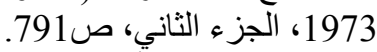
3- حاجي (فريد) وأويدر (عبد الرزاق): الكفاءات العرضية، المركز الوطني للوثائق التربوية، العدد

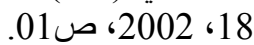

4- ينظر: عبد الوهاب أحمد (الجماعي): كفايات تكوين المعلمين، دار يافا العلمية للنشر والتوزيع،

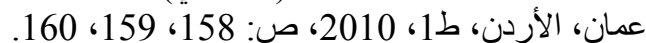
5- ينظر : سهيلة محسن كاظم (الفتلاوي): الكفايات التنريسية، المفهوم ـالتدريب_الأداء، دار الثروق

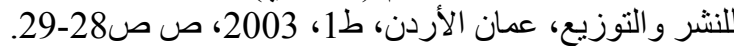

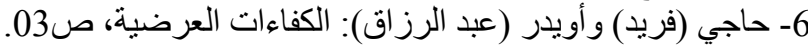
7- ابن جني: الخصائص، تحقيق محمد علي النجار ، الهيئة المصرية صائة العامة للكتاب، ط 4، الجزء الأول

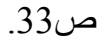

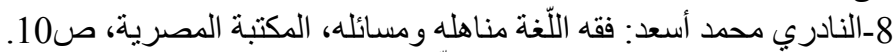

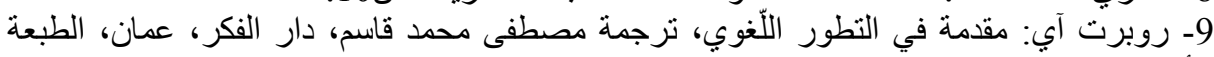

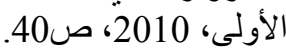

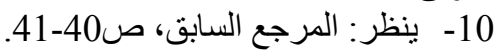

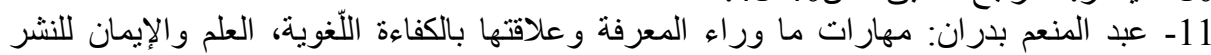

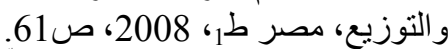

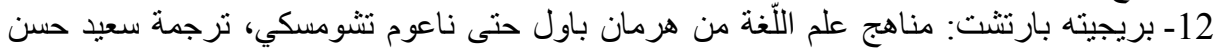

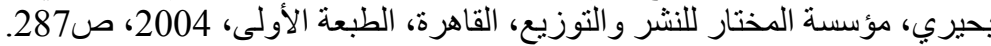

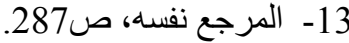

14- عبد المنعم بدران: مهارات ما وال ور اء المعرفة و علاقتها بالكفاءة اللّغوية، العلم و الإيمان، ص64

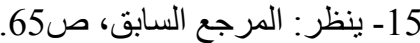
16- روبرت آي: الأصغر ، مقدمة في التطور اللّغوي، ترجمة مصطفى محمد قاسم، دار الفكر، عمان،

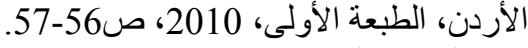

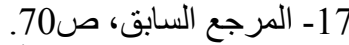
18- ينظر، هادي نهر: الأساس في فقه اللّة العربية وأرومنها، دار الفكر، عمان، الأردن، الطبعة

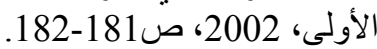

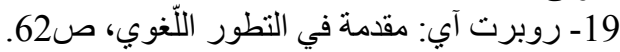

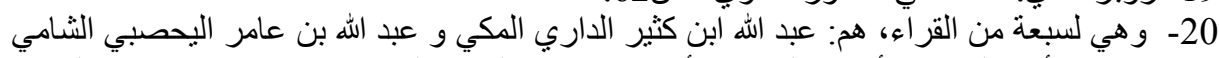

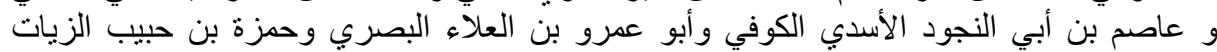

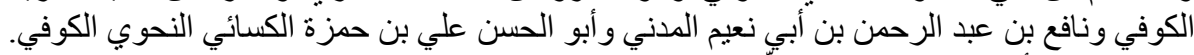
21- "محمد أسعد النادري: فقه اللّغة مناهله ومسائله، المكتبة العصرية، صيدا، بلئ بيروت، 2009،

ـ تحقيق الهمزة وعدمه: كالهمزة المفردة ساكنة (يؤمنون، بئس) أو متحركة (يؤاخذ، يؤلف) قرأهر أها

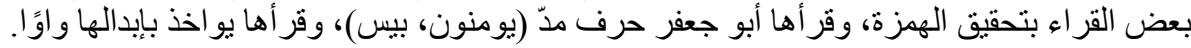


ـ فتح أصوات الحلق و إسكانها، و هي (الهمزة، الهاء، العين، الحاء، الغين، الخاء). فقد قرأ ابن كثير هذه

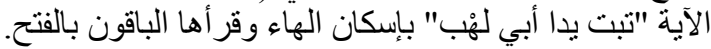

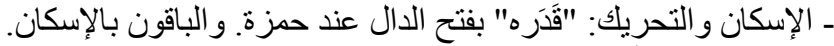

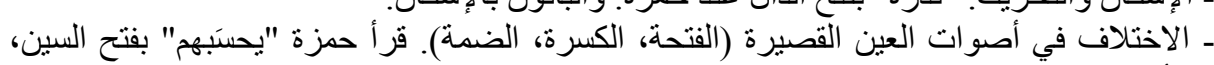

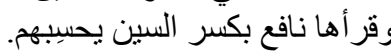
ويقال مثل ذللك في الإظهار و الإدغام و الفتح و الإمالة. 23- 23 نذكر من هذه المصنفات:

ـ الأصو ات اللّغوية لإبر اهيم أنيس.

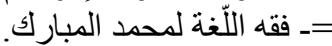

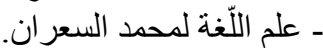

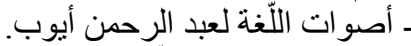

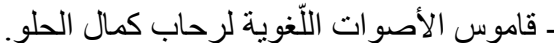
24-رمضان عبد التواب: المدخل إلى علم اللّة ومناهج البحث اللّغوي، مكتبة الخانجي، القاهرة،

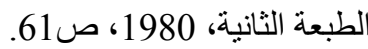

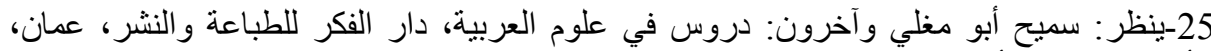

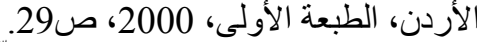
26-صبحي الصالح: دراسات في فقه اللّغة، نقلاً عن محمد أسعد النادري، فقه اللّغة مناهله ومسائله،

27- محمد أسعد النادري: فقه اللّغة، ص257 صن 257.

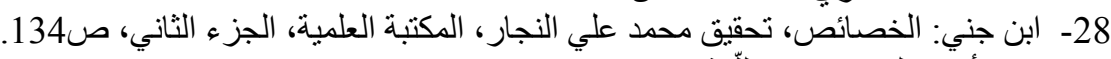

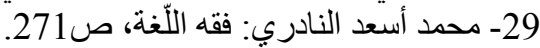
30 - 30 - المرجع نفسه، صدادي: 278-279.

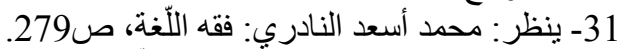
32- من هذه الكتب: عثرات اللسان في اللّغة لعبد القادر البغدادي. معجم الأخطاء الثائعة لـحمد العدناني.

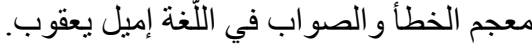

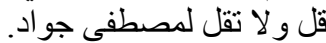
معجم التصويبات اللَّوية ليوسف بكوش. لئل صحح لغناك لناصر لوحيشي.

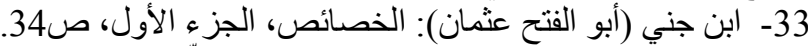

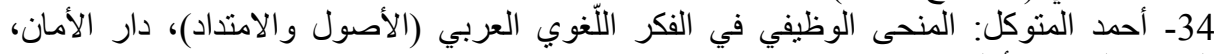

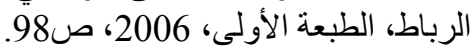

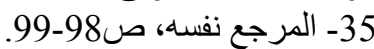

36- ابن فارس (ابو الحسن): الصاحبي في فقه اللّغة العربية ومسائلها وسنن العرب في كلامها، تحقيق

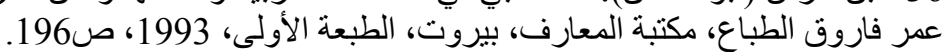

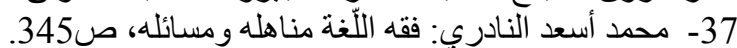

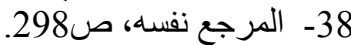

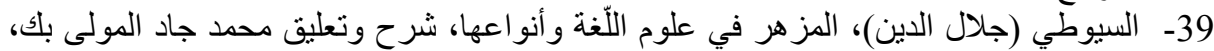

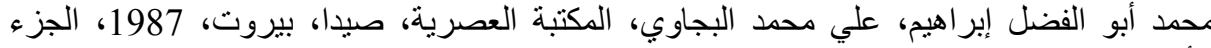

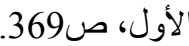

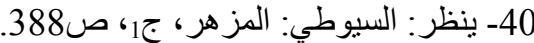

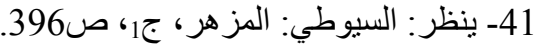




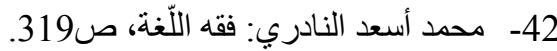

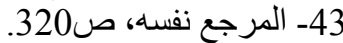

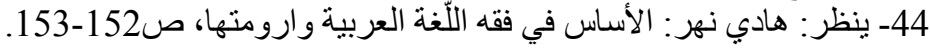

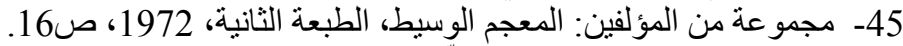

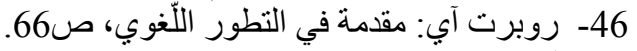

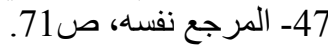

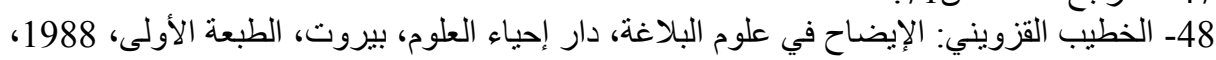

ص13. (13. n

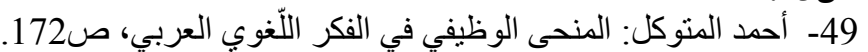

50- السكاكي (ابو يعقوب): مفتاح العلوم، دار الكتب العلمية، بيروت، الطبعة الثانية، 1987،

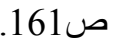

51- السيد أحمد الهاثمي: جواهر البلاغة في المعاني و البيان و البديع، دار الكتب العلمية، بيروت،

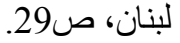

52- شحده فارغ، محمد العناني وآخرون: مقدمة في اللّغويات المعاصرة، دار و ائل للنشر، الطبعة

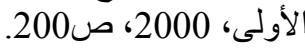

53- المرجع نفسه، ص201-214 